\title{
Children's Garden Consultants: A New Model of Engaging Youth to Inform Garden Design and Programming
}

\author{
Kristi S. Lekies ${ }^{1}$, Marcia Eames-Sheavly ${ }^{2}$, Kimberly J. Wong ${ }^{3}$, and \\ Anne Ceccarini ${ }^{4}$
}

\begin{abstract}
ADDITIONAL INDEX WORDs. youth development, learning activities, recommendations, garden-based learning, youth community action

SumMARY. This paper discusses a unique garden and youth-focused event in which a group of 4-H youth engaged in a "children's garden consultants" program. Over a 3-day period, seven teenaged youth were given the opportunity to actively research children's garden design and educational programming, and then present recommendations to an adult audience of children's garden experts and youth development specialists. Surveys, observations, and discussions with youth, adults in attendance, and program organizers indicated the event was highly valuable and worth repeating. It provided a new learning opportunity for youth, and it also gave adults new perspectives on gardens. The youth's ideas for improving children's gardens and suggestions for future programming are presented as well.
\end{abstract}

A s children's gardens increase in popularity, it is critical that children be involved to the fullest extent possible in their creation. Indeed, concern has been raised that many recreational and educational spaces designed for children by adults are problematic. They do not reflect children's needs or interests; they would not be places children choose for themselves; and opportunities to transform landscapes into rich, multisensory environments that promote healthy development and connection to nature fall short of their potential (Olwig, 1990; Rasmussen, 2004). By not engaging young people in the planning process, children's gardens risk being "places for children" rather than "children's places" that are truly meaningful from a child's point of view (Rasmussen, 2004).

Young people have the capability to make important contributions to the betterment of their communities through planning and discussion, contributing ideas, problem-solving, organizing groups, participating in

Cornell University, Ithaca, NY 14853.

${ }^{1}$ Research Associate, Department of Human Development, Martha Van Rensselaer Hall.

${ }^{2}$ Senior Extension Associate, Department of Horticulture

${ }^{3}$ Research Assistant, Department of Human Development.

${ }^{4}$ Program Assistant, Department of Horticulture. research and evaluation, and working to develop new services (Adams and Ingham, 1998; Checkoway and Richards-Schuster, 2004; Checkoway et al., 2003; Driskell, 2002; Hart, 2002). With respect to the design of outdoor spaces, even children as young as age 3 or 4 years have demonstrated the ability to voice opinions, provide unique knowledge, and contribute to improvements in outdoor play areas (Clark and Moss, 2005). They can identify characteristics of gardens that will make them enjoyable places to be, express some understanding of the tasks and components involved in maintaining a garden, and express likes and dislikes (Whiren, 1995). Older children have shown competence in making decisions about planting, community outreach, recording donations, mapping, testing soil, and building relationships with adult leaders (Canaris, 1995), as well as the actual designing and creating of gardens with a range of elements and themes (Heffernan, 1994). Lucas (1995) advised "putting children at the heart of all aspects of the process of design." They should be involved with teachers, parents, landscape architects, artists, ecologists, child development specialists, and other interested groups in the "multi-professional activity" of developing landscapes. In addition, young people need the experience of tackling local issues to learn how to identify alternatives, effect change, and resolve challenges before they participate in solving the problems of the larger society (Adams and Ingham, 1998).

As a part of its commitment to finding alternative ways to involve children and youth in planning statewide projects, the Cornell University Garden-Based Learning Program invited teenaged youth to participate in a 3-d "children's garden consultants" experience. Program organizers hoped this would serve as a way to engage young people in the planning and designing of gardens for children from birth through adolescence and also add to a growing menu of opportunities for youth engagement. The purpose of this paper is to present information about the usefulness of this model, describe the youth's ideas for improving children's gardens, and identify lessons learned for other groups considering this activity in their own communities.

\section{Materials and methods}

Participants. Participants were recruited from a career explorations event held on the Cornell University campus in Summer 2005. Prior to the event, registration materials were distributed through schools and 4-H programs that described all possible options from which youth could choose. Seven adolescent females from various counties in New York State participated in the children's garden consultants program. Their ages ranged from 15 to 17 years; most were from suburbs, small towns, or rural areas. All had some previous contact with gardening or horticulture prior to their participation in the program, and all were members of their local 4-H club. Four adult chaperones, from different counties, accompanied the participants as required by campus regulations.

Activities. The 3-d event consisted of a mix of presentations, site visits, briefing sessions, assignments and activities, and a final culminating event in which the youth would present their design and programming recommendations for children's gardens. Before arriving at the event, youth were mailed an informational packet containing a list of websites so they would have some familiarity with children's gardens. On the first day, the program began with two presentations, the first given by a landscape architect on the essential elements of planning and design of children's gardens, and the other given 
by the statewide garden-based program leader on educational programming. The youth were informed of their upcoming presentation from the very beginning and were reminded of the presentation throughout the duration of the event. They were divided into two groups-the educational programming team and the design and planning team.

The second day began with a short icebreaker, followed by a presentation on what it means to be a consultant for a program, with detailed guidance regarding what was expected of the youth to prepare and give their presentations the following day. They were also provided with journals to document their observations and ideas as they occurred. They were then taken on field trips to the university public gardens and a local children's garden where they observed the sites, took notes, listened to guest speakers, and asked questions. The afternoon segment consisted of watching a videotape on the Junior Master Gardener program and performing additional internet searches of at least 20 children's garden sites throughout the nation. During this time, they began work in teams on their two presentations using templates provided by the program organizers. In addition, they participated in three garden-based learning activities that were designed to illustrate the various levels of adult involvement-no adult guidance, shared leadership and guidance, and completely adult-led. Following these activities, the youth engaged in a discussion on which level of adult participation was preferable.

The following day consisted of preparing for the presentation and then delivering the presentation to a group of 17 adults. During the preparation time, the youth were functioning independently from the program staff, but a member of the program staff was always present in case the youth needed any assistance with the presentations or the computer equipment.

Flyers were posted in relevant departments across campus, and invitations were given to key individuals involved with children's gardens in the community. In addition, the event was publicized on national gardening listserves, with individuals throughout the United States encouraged to e-mail questions beforehand to bring to the group. The individuals in attendance were actively engaged in educational activities related to youth, youth community action, children's gardens, and horticulture. Each group gave a 15-min presentation to the audience, and then answered questions from audience members as well as those sent in by e-mail.

It should be noted that the chaperones were given specific tasks to do throughout the 3 -d event. From the beginning they were informed that the purpose of the event was to allow youth to experience a new role as consultants, and that it was essential that youth perspectives be as free from as much adult bias as possible. Adult chaperones were asked to observe the activities and let the youth ask and answer questions. In addition, these adults were asked to review existing garden-based learning websites for youth educators in an effort to occupy their time, provide them with resources, and give the youth their own space and time to work on their presentations. The adults also assisted program organizers with preparation for activities and played an integral role in demonstrating the various levels of adult participation.

Information regarding the usefulness of this model was gathered from four groups of individuals: the seven youth participants, 14 of the 17 adults who attended the presentation, the two program organizers, and two observers. Youth completed an initial survey that asked about their previous background in gardening and outdoor activities, as well as an evaluation form at the end of the event. They also participated in a focus group in which they reflected upon their experience and provided suggestions for future events. The adults completed feedback forms that inquired about their perspectives of the presentation and whether youth perspectives were different from their own. The program organizers were interviewed about the perceived success or failure of the event, their observations, areas for improvement, and suggestions for other groups wishing to pursue this type of opportunity. Observers were present at activities throughout the $3-\mathrm{d}$ event and engaged in additional discussion with the organizers about their perceptions.

\section{Results and discussion}

USEFULNESS OF CHILDREN'S GARDEN CONSULTANTS MODEL. All groups felt this was a valuable activity and worth being repeated. The youth rated their overall experience as a children's garden consultant very highly (between "good" and "excellent"). They enjoyed most of the activities, which they described as both fun and educational. When asked what they liked best about the program, they responded with comments such as, "the equality between the adults and consultants," "how we could teach the adults and also learn in return," and "I used my mind and could voice my opinion.” A number of the youth stated that they would present the idea of a children's garden to their local 4-H clubs. The adults who attended the presentation and the program organizers also felt the event was successful. Many indicated that youth perspectives differed from adult perspectives in various ways, and all learned new ideas for children's gardens.

YOUTH'S IDEAS FOR IMPROVING CHILDREN'S GARDENS. Each team defined a children's garden and listed essential elements. They also discussed what does not work, determined what was missing, and made recommendations for improvement from the perspective of educational programming or garden design and planning.

The educational programming team presented a number of ideas regarding the staffing, activities, and other aspects of children's gardens. First, they suggested that children's gardens should employ passionate staff members in an effort to increase interest of children and youth. They also recommended having an inviting environment, one that is both educational and fun, and setting up an interactive website and an information center. Specific suggestions for the garden were to include wildlife, a wide variety of programs, product-crop association, and the use of community sponsors. In addition, they included a list of undesired features, such as long talking tours, charged admission, a lack of activities for older children and families, and a strictly educational focus that lacked fun components. They also composed a list of missing features that they would like to see in future children's gardens, which included international aspects, a community pool, a "bad example" garden (a poorly maintained garden, to use as an example of what not to do), and conservation classes. Finally, the youth stressed the importance of donations, community involvement, 
Table 1. Suggestions provided by teenaged youth participating in the educational programming team, the first of two groups attending a "children's garden consultants" 3 -d event that culminated in group presentations.

- Employ passionate staff members

- Create an inviting environment that is educational and fun

- Set up interactive website and information center

- Include wildlife, a wide variety of programs, and product-crop association

- Use community sponsors

- Avoid long talking tours, charged admission, and a strict educational focus

- Develop activities for older children and families

- Include international aspects, a community pool, a "bad example" garden, and conservation classes

- Incorporate donations, community involvement, intergenerational activities, hands-on tours, and nature-related fine art intergenerational activities, hands-on tours, and the presence of naturerelated fine art. These ideas are summarized in Table 1.

The design and planning team emphasized safety, maintaining a child/youth focus, and providing opportunities for physical and sensory exploration. They asserted that the essential elements of a children's garden were smaller-scale play areas and objects, safe play areas, secure boundaries, safe and accessible pathways, and components that provide educational opportunities as well as enjoyment. Some specific design elements that the youth recommended were tall mazes, waterfalls, slides, spaces with a sense of enclosure, sculptures, animals, fountains, butterfly gardens, and trees and covered structures for shade. They expressed particular interest in having living sculpture in the gardens, such as grass-covered furniture that children could climb and explore. They also expressed interest in living sculpture for older children and teenaged youth, stating that too often, "teenagers don't go outside anymore." The youth indicated strong dislike of certain features including concrete pathways, large metal fences, sites by major roadways, picnic tables, nude statues, plastic and fiberglass features, and anything that gave the garden an "amusement park" feeling. Among their list of missing elements for children's gardens were transportation (e.g., trains or boats), stages for performances, natural pathways, hanging vines, wading pools, fish ponds, "freedom areas" (e.g., large grassy areas to play in and explore), bridges over waterways, and words written with grass or plants. See Table 2.

Adults noted that the youth perspective was "lively" and combined educational activities with fun. However, they also felt that adults often have a better understanding of the realities and challenges of designing a children's garden, such as safety considerations and funding constraints. They indicated that they learned many new lessons from the youth's presentations, including the use of the children's garden as an intergenerational gathering spot, the benefits of using grass chairs and living sculptures, young people enjoying their roles as consultants, specific ideas for garden design, and the strong dislike of gardens that resemble theme or amusement parks.

SUGGESTIONS FOR IMPROVEMENT. The participating youth, adult audience members, and the program organizers deemed the program as an overall success. For other groups considering similar opportunities, this event provided a number of lessons learned.

Follow-up interviews with the youth revealed that they would have liked more specific information about the program in advance. As this was a new role for them, they were unclear about what the duties, responsibilities, and expectations of being a consultant would entail. They felt that a better understanding beforehand could help prepare youth for the experience and engage them to a greater extent once the activities begin. Adult leaders considering a similar event are encouraged to clearly describe the program, such as through a letter or other registration materials, when recruiting youth for this unique event.

The most useful activities of the program, according to youth survey responses, were the small group discussions with the other youth consultants, the internet search activity, and the field trip to the university gardens. However, they were less favorable about the Junior Master Gardener video, keeping a journal, and guest speaker lecturers. It should be noted that the program organizers felt that the guest speakers presented something other than what they had requested. Future programs could benefit by giving their guest speakers very clear expectations about the goals of the program and what should be covered in the presentations, and by taking additional care to select speakers with a reputation for relating well to adolescent audiences. In addition, program organizers felt it would be useful to prepare a "tool kit" with model presentations for guest speakers to reference or draw from.

Of particular concern to the organizers was the potential for adults to bias the views of the youth or to assume responsibility for work the youth should be doing. They indicated that adult interference could be minimized by talking with any parents or adult chaperones beforehand and clearly articulating the goals of the program. For example, a briefing session at the beginning of the program could resolve ambiguities about the adult role and
Table 2. Suggestions provided by teenaged youth participating in the design and planning team, the second of two groups attending a "children's garden consultants" 3-d event that culminated in group presentations.

- Design smaller-scale play areas and objects

- Keep play areas safe

- Keep pathways accessible

- Include tall mazes, waterfalls, slides, spaces with a sense of enclosure, animals, fountains, butterfly gardens, trees, and covered structures

- Consider living sculpture, such as grass-covered furniture

- Avoid concrete pathways, metal fences, picnic tables, nude statues, plastic and fiberglass features, and anything that creates an "amusement park" feeling

- Avoid sites by major roadways

- Include bridges, words written with grass or plants, and "freedom areas"

- Design a stage for performances

- Incorporate transportation in the garden, hanging vines, wading pools, and fish ponds 
would reduce the potential for interference. Furthermore, it is essential that activities be constructed for the adults so that they are engaged in meaningful roles throughout the duration of the program. Organizers should be observant and be prepared to talk to any adults who may be "taking over" for the youth or otherwise influencing the youth involvement process.

When asked if anything about the program should be changed, both the youth and the program organizers felt that future children's garden consultant programs should provide an opportunity to meet with children to discuss ideas for children's gardens. Although this was originally a part of the schedule, time and logistical constraints required that this component be dropped. For future programs, the opportunity to talk with children of different ages would be beneficial and provide the youth and adult audiences with additional insights.

The youth needed some adult guidance throughout the 3 -d event to guide them through the various activities, assist with travel to the various sites, and provide overall direction. This event was planned by an experienced educator and a recent college graduate, both of whom could relate well to youth. It was apparent that the youth enjoyed interacting with younger program staff members (college-aged) who served as peers and mentors. It is recommended that adults developing these programs consider engaging young people to serve in this capacity.

The youth felt they had adequate time to prepare for the presentations. The presentation template was valuable in that it minimized the amount of time devoted to formatting and learning the program instead of preparing the presentation. Should more time be available, youth could be provided with more opportunities to learn to use this program. Another suggestion would be to assist the participants in how to effectively organize and prepare for a presentation, particularly if they have had limited public speaking experience. Some public speaking tips also could be provided prior to the presentation.

Finally, serving as a children's garden consultant was a new role for these youth-one which they learned from and also enjoyed. Another suggestion for future programming is to discuss with youth the ways in which they can contribute their new knowledge and ideas in other settings after the program has ended. For example, several participants mentioned their plans to give presentations at their local $4-\mathrm{H}$ clubs. In short, the youth should be made aware of opportunities and outlets for their newly formed perspectives and knowledge.

\section{Conclusion}

The children's garden consultants model is an effective way to engage teenaged youth in a process through which they can inform adults of their perspectives regarding garden-based learning programming and children's garden design. An ideal format minimizes "talk time"; it maximizes opportunities to visit gardens locally and via the internet, reviews approaches to garden-based learning activities, encourages interaction with one another and with younger children, and prepares for a presentation using well-designed templates. A satisfactory format also prepares adults for the experience, and clearly lays out expectations of youth in advance.

This project clearly supported the need to engage youth in roles beyond traditional garden-based learning activities. In addition to indicating that they learned significantly about all aspects of children's garden settings, the program clearly sparked an interest among teenaged youth, and the desire to repeat exciting elements when they returned home. They appreciated being viewed as experts and as partners.

As adults seek ways to genuinely engage youth in the process of garden planning and design, this model could serve as a beginning point for learning how youth define gardens, what they view as essential elements, and what they believe does not work well in a garden setting, is missing from traditional approaches, or should be improved. Youth clearly learned from this experience and had important contributions to make.

\section{Literature cited}

Adams, A. and S. Ingham. 1998. Changing places: Children's participation in environmental planning. Children's Soc., London.

Canaris, I. 1995. Growing foods for growing minds: Integrating gardening and nutrition education into the total curriculum. Children's Environ. 12(2):264-270.

Checkoway, B.C. and K. Richards-Schuster. 2004. Youth participation in evaluation and research as a way of lifting new voices. Children Youth Environ. 14(2):84-98.

Checkoway, B., K. Richards-Schuster, S. Abdullah, M. Aragon, E. Facio, L. Figueroa, E. Reddy, M. Welsh, and A. White. 2003. Young people as competent citizens. Community Dev. J. 38(4):298-309.

Clark, A. and P. Moss. 2005. Spaces to play: More listening to young children using the Mosaic approach. Natl. Children's Bur., London.

Driskell, D. 2002. Creating better cities with children and youth: A manual for participation. United Nations Educ., Sci., and Cultural Org. (UNESCO)/Earthscan, London and Sterling, U.K.

Hart, R.A. 2002. Children's participation. United Nations Children's Fund (UNICEF)/Earthscan, London.

Heffernan, M. 1994. The children's garden project at River Farm. Children's Environ. 11(3):221-231.

Lucas, B. 1995. Learning through landscapes: An organization's attempt to move school grounds to the top of the educational agenda. Children's Environ. 12(2):223-244.

Olwig, K.R. 1990. Designs upon children's special places? Children's Environ. Quarterly 7(4):47-53.

Rasmussen, K. 2004. Places for children-Children's places. Childhood 11(2):155-173.

Whiren, A.P. 1995. Planning a garden from a child's perspective. Children's Environ. 12(2):250-255. 